\title{
Prototyping a Disciplinary Information Space for a New Smart Learning Management System Based on IMS-LD and NoSQL
}

\author{
https://doi.org/10.3991/ijes.v8i4.19071 \\ Mohammed Ouadoud ${ }^{(\varpi)}$ \\ Abdelmalek Essaadi University, Tetouan, Morocco \\ mohammed. ouadoudegmail.com \\ Tarik Marrakchi \\ Hassan II University of Casablanca, Casablanca, Morocco \\ Rajae Taghzout \\ Sidi Mohammed Ben Abdellah University Fez, Fez, Morocco
}

\begin{abstract}
This work is mainly based on the prototyping of a disciplinary information space for a new LMS. Our work is first to think about the conditions for creating a real LMS between learners and teachers. We have chosen to base ourselves on the hybridization between four learning theories as the basis for teaching this LMS, namely traditional pedagogy, behaviorism, cognitivism and social constructivism. These pedagogies have already proven themselves, mainly in classroom learning situations. The LMS consists of different activity spaces for teaching and learning activities. We limit ourselves in this work to the prototyping of disciplinary information space for a new LMS based on IMS-LD, NoSQL MongoDB database, and Symfony framework.
\end{abstract}

Keywords-LMS, IMS-LD, eLearning platform, designing an IMS-LD,

NoSQL, Symfony Framework, disciplinary information space

\section{Introduction}

We present a simple disciplinary information model of our new LMS for creating and administering educational content online. This tool allows you to generate and edit website structures through a database rather than pedagogical models, with a variety of choices that ensure better adaptation to the course teaching and learning style.

To model the disciplinary information space, we based ourselves on the IMS-LD specification by focusing on four learning theories deemed most relevant for our modeling, namely traditional pedagogy, behaviorism, cognitivism and social constructivism. Then, some learning theories that have long inspired the design of computer applications are combined and put into perspective with several emerging educational features to build an original modeling of the disciplinary information space of our new LMS. 
The IMS-LD specification or instructional design engineering uses pedagogical concepts, allowing to model learning units. IMS-LD takes into account a wide variety of teaching models it is there its flexibility. A course plan extract of a general or specific database can be modeled with IMS-LD, through the description of the different roles, activities, environments, methods, properties, conditions, and notifications. It is used to transform the course plans into formal learning units (UOL) that can be performed with an IMS-LD editor based on an engine such as Copper core [18]. These executable units can be designed from the beginning using an editor such as Reload [19].

Several models of LMSs have been developed previously [13, 14, 15, 16, 17], but they have been abandoned because the life cycle of these LMSs evolves rapidly. Therefore, we conducted an analytical study on free LMSs. This based on an approach to assess the quality of LMSs $[1,2,3,21]$. Based on this research, which seemed to us incomplete, we proposed a design portrait of an IMS-LD model of the disciplinary information space for our new LMSs. The latter is anthropocentric and is based on a learning concept, which is at the intersection of the most used learning theories. In fact, the idea is to orient research towards optimal compatibility between the services offered by LMSs and the needs of learners, for better optimization of online learning.

This paper mainly includes several important sections:

- We start by general introduction of paper with the objectives of this work

- Then we will determine the LMS and the underlying activity spaces

- Thereafter, we specify the IMS-LD concept which constitute the cornerstone of this study

- We model the disciplinary information space of the LMS based on the IMS-LD, after generating the IMS-LD meta-model of the disciplinary information space

- Therefore, we design the disciplinary information model based on the MongoDB database

- Finally, we contribute our work by prototyping the disciplinary information model based on the Symfony framework.

\section{$2 \quad$ LMS and the Activity Spaces}

The LMS consists of different activity spaces for activities of teaching and learning $[8,9,12]$. Each model represents a space, in these spaces, both teachers and learners can have a:

- Disciplinary information space

- Communication space

- Collaboration space

- Sharing space

- Evaluation space

- Production space

- Self-management space

- Assistance space 


\section{Instructional Management Systems - Learning Design}

IMS-LD was published in 2003 by the IMS/GL ${ }^{1}$. The source $\left(\mathrm{EML}^{2}\right)$ of the proposed language was assessed by the European Committee for Standardization (CEN) in a comparative study of different SRMS [5, 7]. EML is defined by CEN / ISS as "an information aggregation and semantic model describing the content and processes involved in a unit of learning from an educational perspective and to ensure the reusability and interoperability." [23]. In this context, the North American IMS consortium undertook a study and provided a specification of such a language, giving birth in February 2003, the Learning Design specification V1.0 (IMS-LD). She adds that proposal, largely inspired EML developed by $[6,7]$ (OUNL) provides a conceptual framework for modeling a Learning Unit and claims to offer a good compromise between on the one hand to the generic implement a variety of instructional approaches and secondly, the power of expression that allows an accurate description of each learning unit.

\section{Modeling a Disciplinary Information Based on IMS-LD}

We carry out the design of our LMS model without using the transformation based on the rules of the ATL language, because we detected a semantic loss during the transformation of the model.

This led us to develop our model through the broad lines of the diagram in which we will eventually identify the characteristics of the constituent entities of our class diagram, in which we will specify the constituents of the different classes for the disciplinary information space.

\subsection{Use case diagram}

Use case diagrams identify the functionality provided by the use case; users interact with actors and interactions between them. Figure 1 describes the use case diagram of the disciplinary information space representing the external actors who will interact with the system.

\subsection{Correspondence between the terminology of IMS-LD and that of the disciplinary information model}

We try to adapt the IMS-LD model to our model. This adaptation will go through three stages, firstly, the development of the disciplinary information model. Second, the study of the correspondence between the developed model. Finally, the IMS-LD model and their transformation into an IMS-LD model based on the ATL language. However, we design our model without using the transformation based on the rules of the ATL language, because we detected the same problems as in this works $[10,20,23,11,22$,

${ }^{1}$ IMS/GLC: Instructional Management Systems Global Learning Consortium

${ }^{2}$ EML: Educational Modelling Language. 
$24,25,26,4]$. In IMS-LD, we do not have the possibility of building a course, which consists of several chapters; because, there is at this level a semantic loss.

The majority of the classes designed in our model correspond perfectly to the IMSLD model, which allows their transformations. Model transformation is a technique that aims to put links between models to avoid unnecessary reproductions. In Table 1, we have tried to collect all the classes of the disciplinary information space and their equivalent to IMS-LD.

Table 1. Correspondence between the terminology of IMS-LD and that of the disciplinary information model

\begin{tabular}{|l|l|}
\hline \multicolumn{1}{|c|}{ Disciplinary information model } & \multicolumn{1}{c|}{ IMS-LD model } \\
\hline Prerequisite & Prerequisite \\
\hline Phase & Play \\
\hline The role, and features & Role \\
\hline Members & Person \\
\hline Coordinator, tutor, and teacher & Staff \\
\hline Learner & Learner \\
\hline Objective & Learning Objective \\
\hline Activity space & Environment \\
\hline Course, chapter, section, and block & Learning Object \\
\hline Disciplinary information space & Services \\
\hline
\end{tabular}

\subsection{IMS-LD class diagram}

We create a model based on the theoretical study of our current work and we try to recognize our model with the IMS-LD model. We will use the same IMS-LD terminology for all the classes of our proposed model. There is an equivalent class in the IMS$\mathrm{LD}$, for the different classes of our model (see table 1). 
Table 2. Table function description

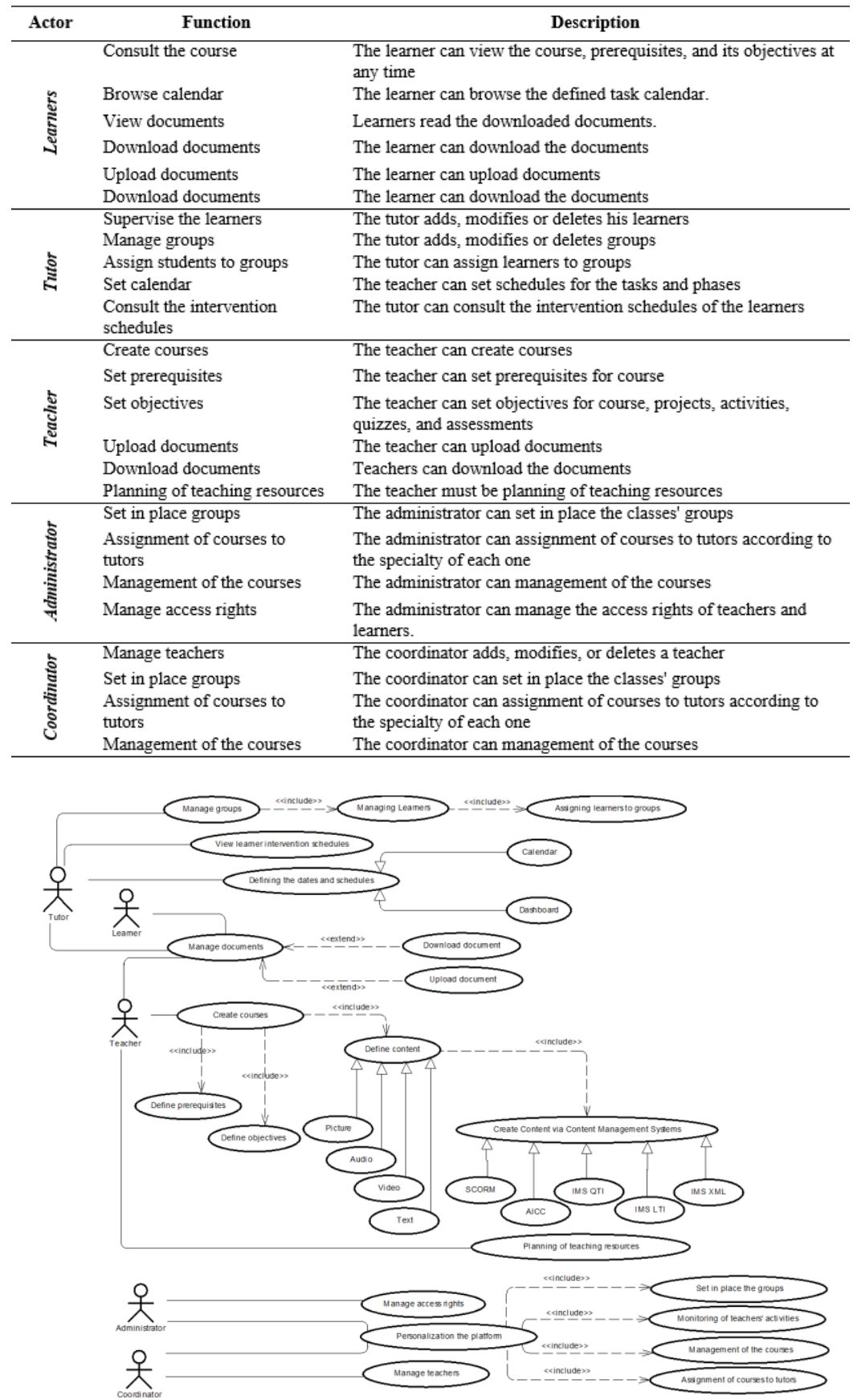

Fig. 1. Use Case Diagram of disciplinary information space 
We propose the following class diagram (see Figure 2), as a model of disciplinary information space, which meets the needs of teachers and learners.

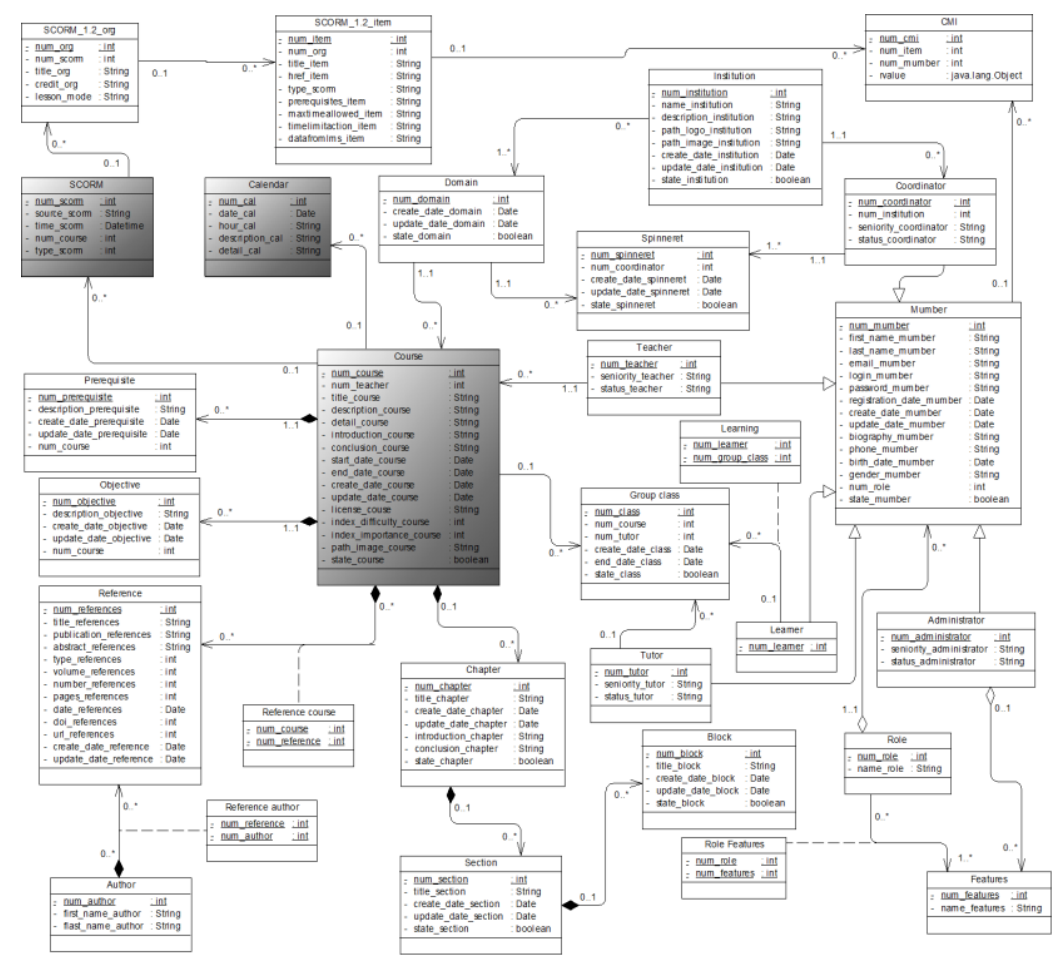

Fig. 2. Class Diagram of disciplinary information space for LMS

\section{Designing a Disciplinary Information Space for LMS Based on MongoDB Database}

MongoDB database is a free, open source document-oriented database program. Classified as a NoSQL database program. MongoDB uses JSON type documents with schemas. It supports field, range, and regular expression queries. Queries can return specific document fields and include user-defined JavaScript functions.

We have chosen to design our LMS via the NoSQL MongoDB database, for many functionalities:

- Flexibility. It is the ability to store different types of data in your document

- Speed. NoSQL databases takes less time to access data than SQL

- Continuous backups. Via NoSQL Mongo database, which includes a continuous backup solution with point and instant request

- In addition, comprehensive monitoring and customizable alerts. 
Table 3 describes the course collections of the MongoDB database of the disciplinary information space representing only the external actors who will interact with the system.

Table 3. Course collections of MongoDB NoSQL database of the disciplinary information space

\begin{tabular}{|c|c|}
\hline Course Collection & Reference Collection \\
\hline \multirow{3}{*}{ 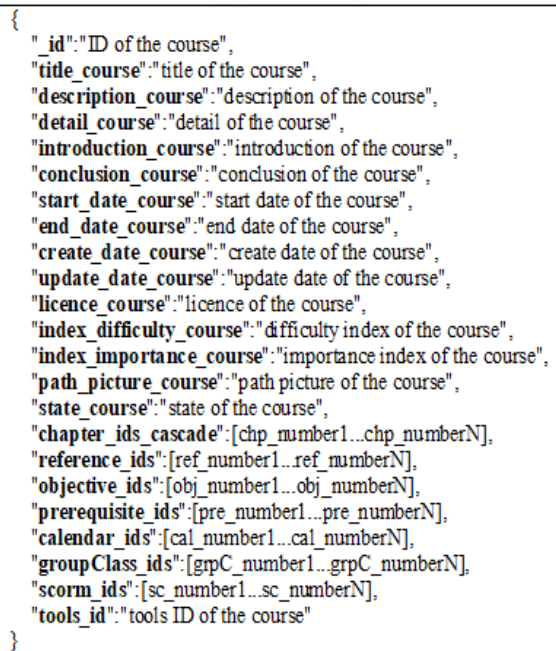 } & 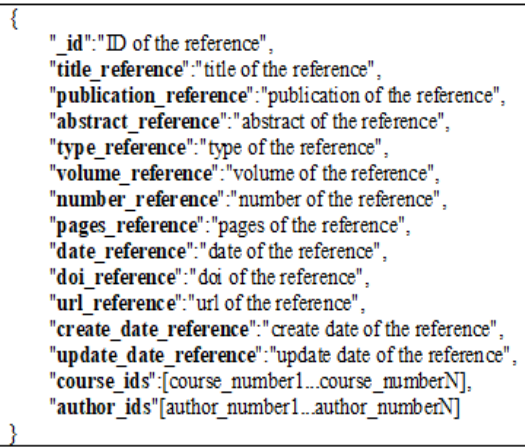 \\
\hline & Author Collection \\
\hline & $\begin{array}{l}\text { \{ } \\
\text { "id":" "D of the author" } \\
\text { "first_name_author":"first name of the author", } \\
\text { "last_name_author":"last name of the author", } \\
\text { "reference_ids"[reference_number1...reference numberN] } \\
\text { \} }\end{array}$ \\
\hline $\begin{array}{c}\text { Chapter Collection } \\
\end{array}$ & Section Collection \\
\hline $\begin{array}{l}\text { \{ } \\
\text { "id":"D of the chapter", } \\
\text { "title_chapter":":title of the chapter", } \\
\text { "create_date_chapter":" create date of the chapter", } \\
\text { "update_date_chapter":"update date of the chapter", } \\
\text { "introduction_chapter":":introduction of the chapter", } \\
\text { "conclusion_chapter":"conclusion of the chapter", } \\
\text { "state_chapter":" state of the chapter", } \\
\text { "course_id":"course D of the chapter", } \\
\text { "section_ids_cascade"::[sec_number 1...sec_number N] } \\
\text { \} }\end{array}$ & $\begin{array}{l}\text { "_id":" } \mathbb{D} \text { of the section", } \\
\text { "title_section"::"title of the section", } \\
\text { "create_date_section"::"create date of the section", } \\
\text { "update_date_section":"update date of the section", } \\
\text { "state_section" ": state of the section", } \\
\text { "chapter_id":" chapter D of the section", } \\
\text { "block_ids_cascade":[blc_number 1...block number N] }\end{array}$ \\
\hline \multicolumn{2}{|l|}{ 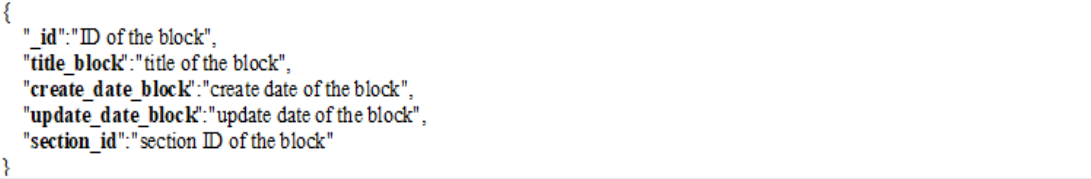 } \\
\hline $\begin{array}{c}\text { Prerequisite Collection } \\
\end{array}$ & Objective Collection \\
\hline 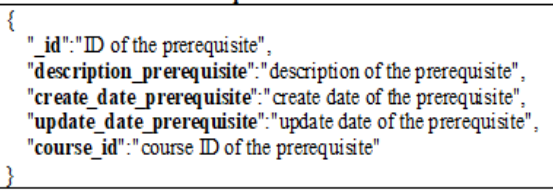 & 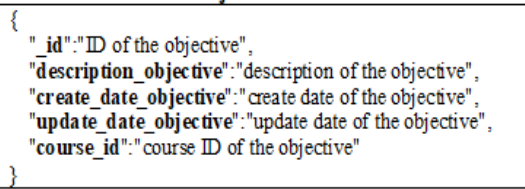 \\
\hline
\end{tabular}




\section{$6 \quad$ Prototyping a Disciplinary Information Space Based on Symfony Framework}

\subsection{Symfony framework}

We have chosen to develop our LMS via the Symfony framework, for the following objectives:

- It aims to speed up the creation and maintenance of websites

- It has a low performance overload used with a bytecode cache

- It aims to create robust websites and aims to give developers full control over the configuration.

Table 3 describes the schema of the course and chapter collections of the NoSQL MongoDB database, of the disciplinary information space.

\subsection{Prototyping a disciplinary information space}

In this subsection, we limit ourselves to presenting the general information interface of the course in the disciplinary information space.

General information interface: In the latter (see Figure 3), the author/teacher has several privileges, which he needs for the creation of a course, which respects academic standards. For this, we have given the author/teacher the right to:

- Add a general title, an image, and a short description of a course, which are displayed when the course appears for the first time

- Add a short introduction, the details, and the conclusion of a course, which are displayed if the learner wants to see more details about the course

- Select the start and end date of a course, which indicates the duration of a course session, thus, they allow you to close the session if the course duration has elapsed

- Determine the license of a course, to respect copyright

- Add the difficulty index of a course, to recommend the courses adapted to the level of each learner

- Choose the language of a course, to recommend the course adapted to each learner

- Choose the course area, to simplify the search for a course by area. 


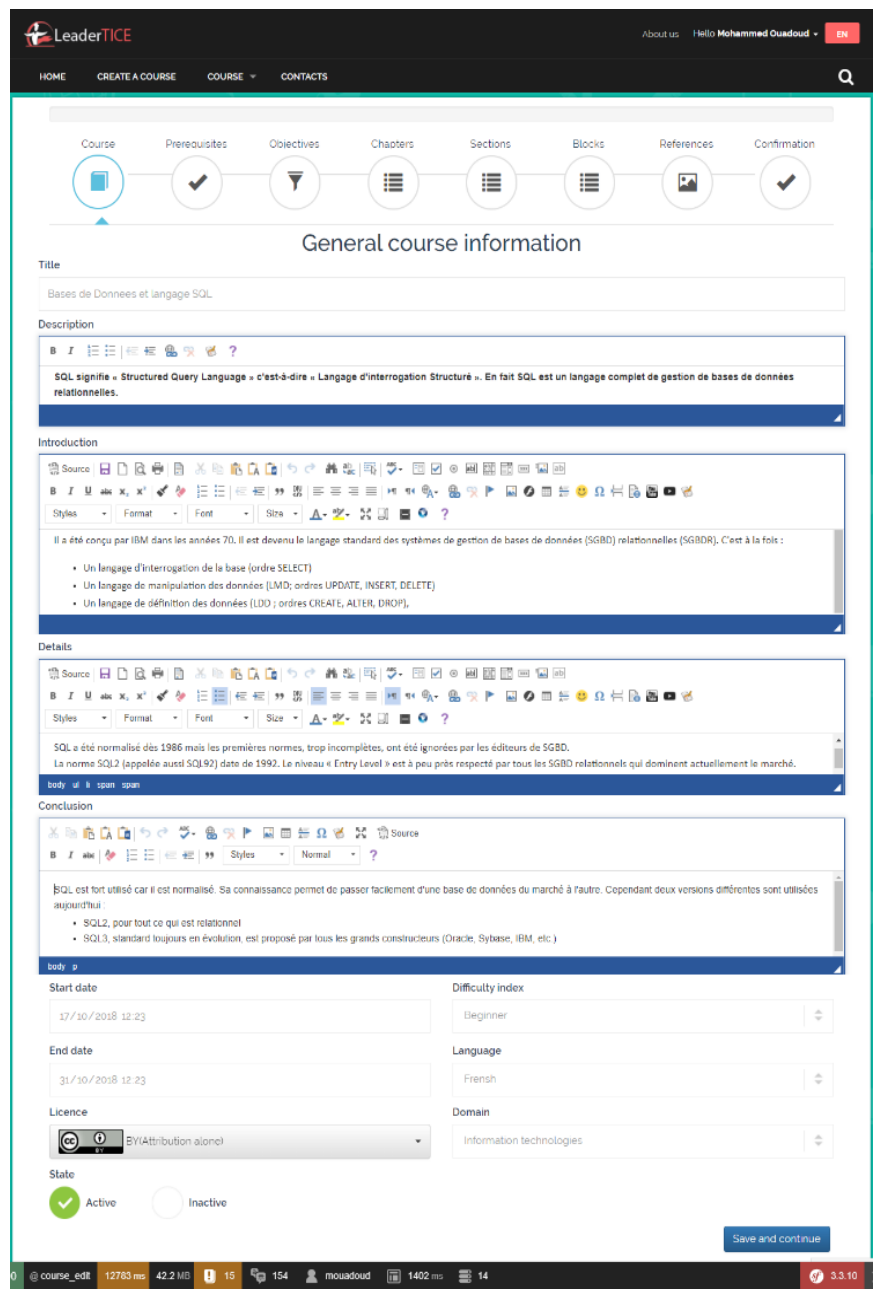

Fig. 3. General information interface of the course developed by the NoSQL MongoDB database and the Symfony framework

The prerequisite course interface: In the course prerequisite interface (see Figure 4); the author/teacher has several privileges, which he needs to create the objectives of a course that meet academic standards. For this, we have given the author/teacher the right to quote the prerequisites so that the learner can start the session of the course. 


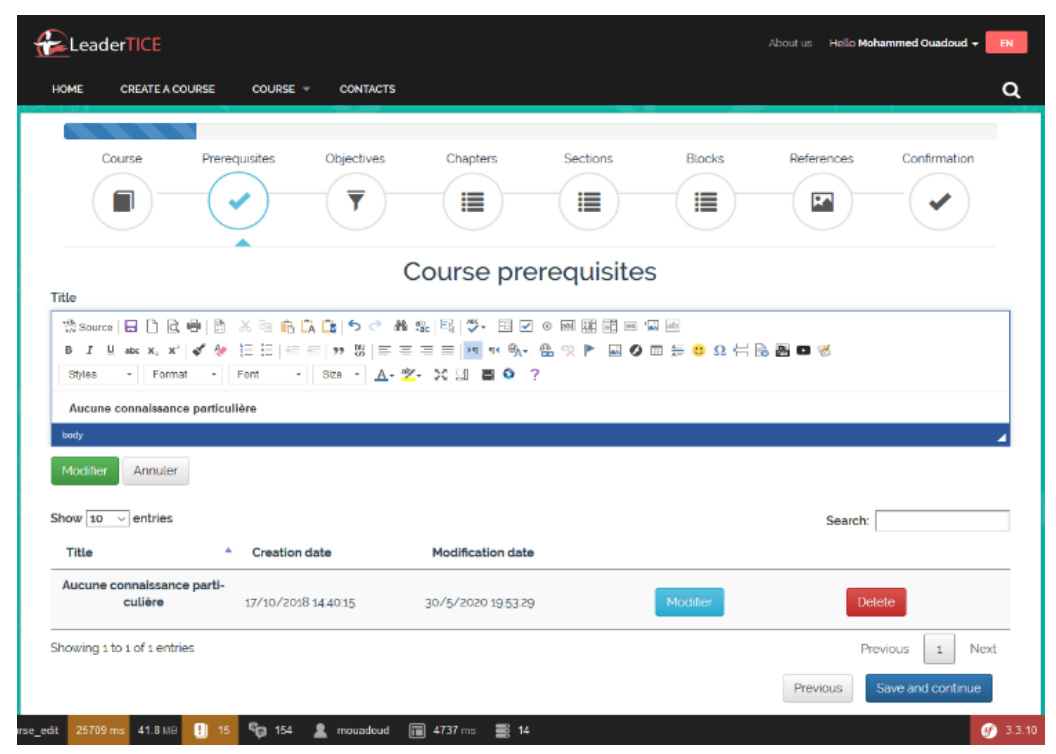

Fig. 4. Course prerequisite interface developed by the NoSQL MongoDB database and the Symfony framework

The course objectives interface: In the course objectives interface (see Figure 5), the author/teacher has several privileges, which he needs to create the objectives of a course that meet academic standards. For this, we have given the author/teacher the right to cite all the objectives of the course so that the learner can determine if the course meets his needs.

The course chapters interface: In the chapters interface of the course (see Figure 6 , the author/teacher has several privileges, which he needs for the creation of the chapters of a course which respect the academic standards. For this, we have given the author/teacher the right to insert the title, introduction, and conclusion of all chapters of a course that the learner can determine if the course meets his needs.

To make the chapters of the course active, by clicking on the checkbox "active", if the chapters are well written, or leave it inactive, by clicking on the checkbox "inactive", if the chapters require certain modifications.

- Make the general course information active, by clicking on the "active" checkbox, if the general course information is well written, or leave it inactive, by clicking on the "inactive" checkbox, if the general information of the course requires certain modifications.

The sections interface of a chapter: In the section interface of a course chapter (see Figure 7), the author/teacher has several privileges, which he needs for the creation of chapter sections that comply with academic standards. For this, we have given the author/teacher the right to choose the chapter in which he wants to add sections. For each section of a selected chapter, the author/teacher can insert the title of the section and the type of media to use (text, audio, video, etc). 
To make the section active, by clicking on the "active" checkbox, if the section information is well written or leave it inactive, by clicking on the "inactive" checkbox, if the section information requires some modifications.

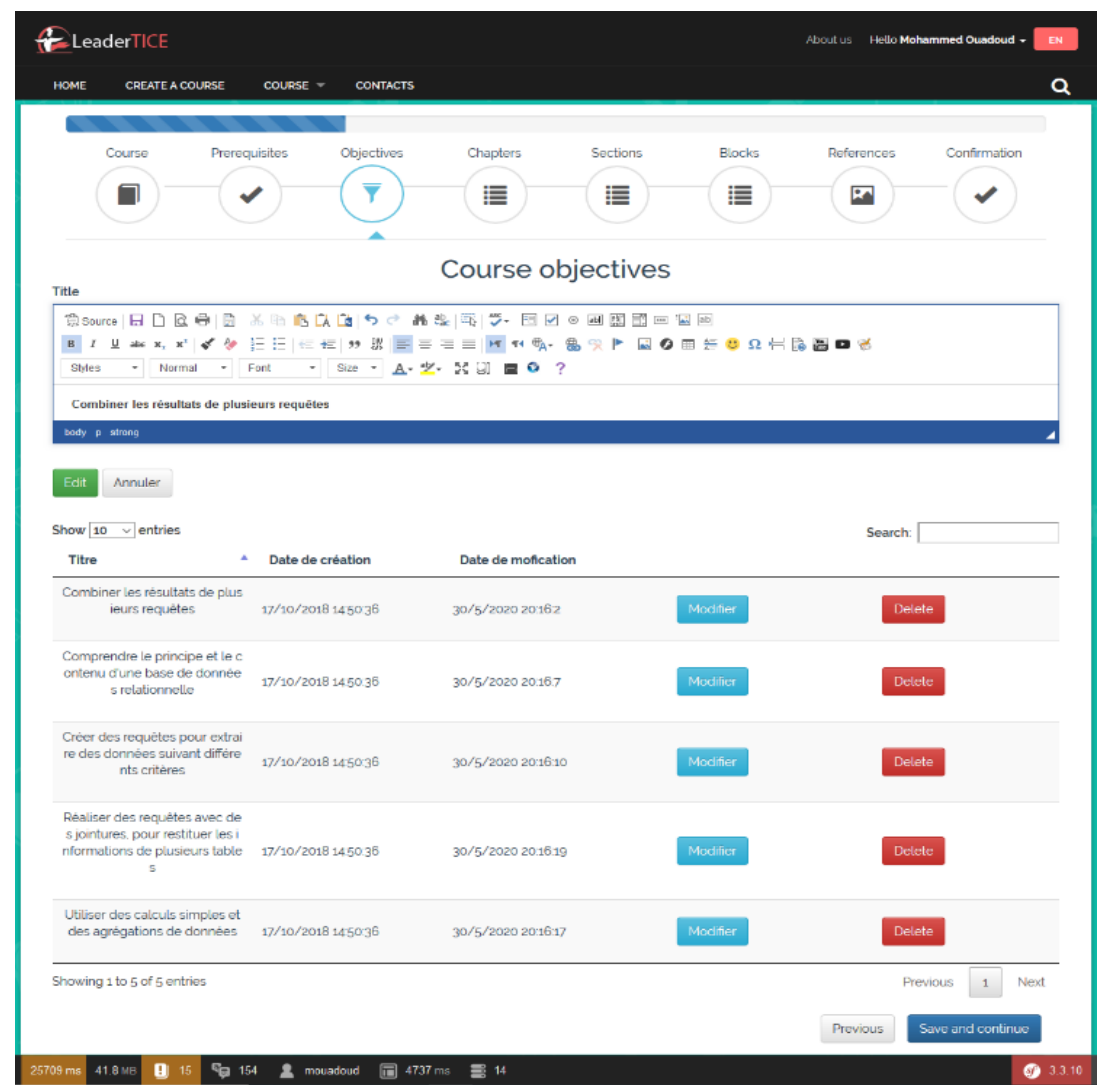

Fig. 5. Course objectives interface developed by the NoSQL MongoDB database and the Symfony framework 


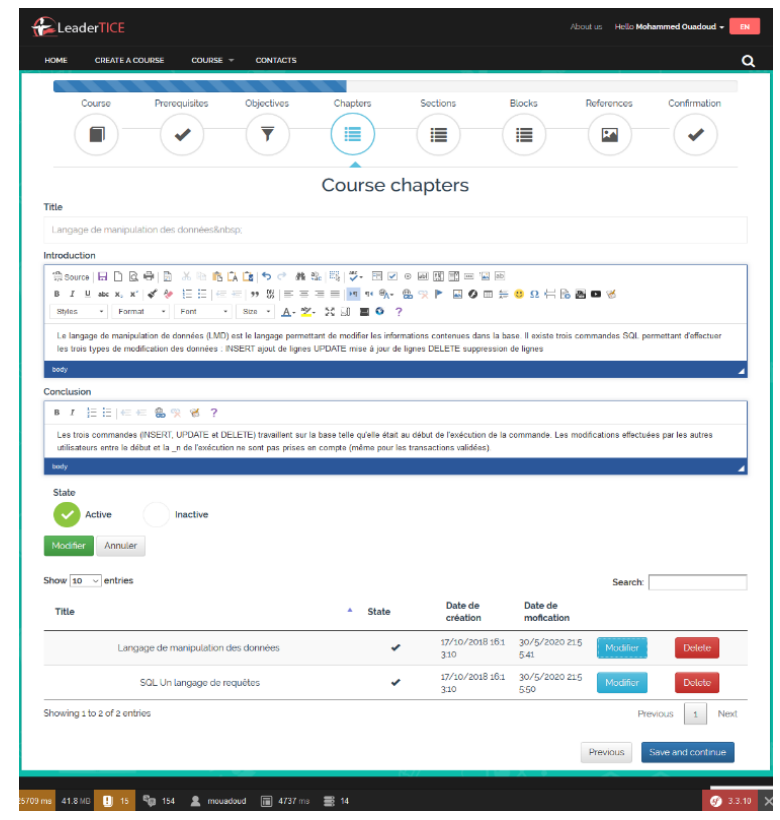

Fig. 6. Course chapters interface developed by the NoSQL MongoDB database and the Symfony framework

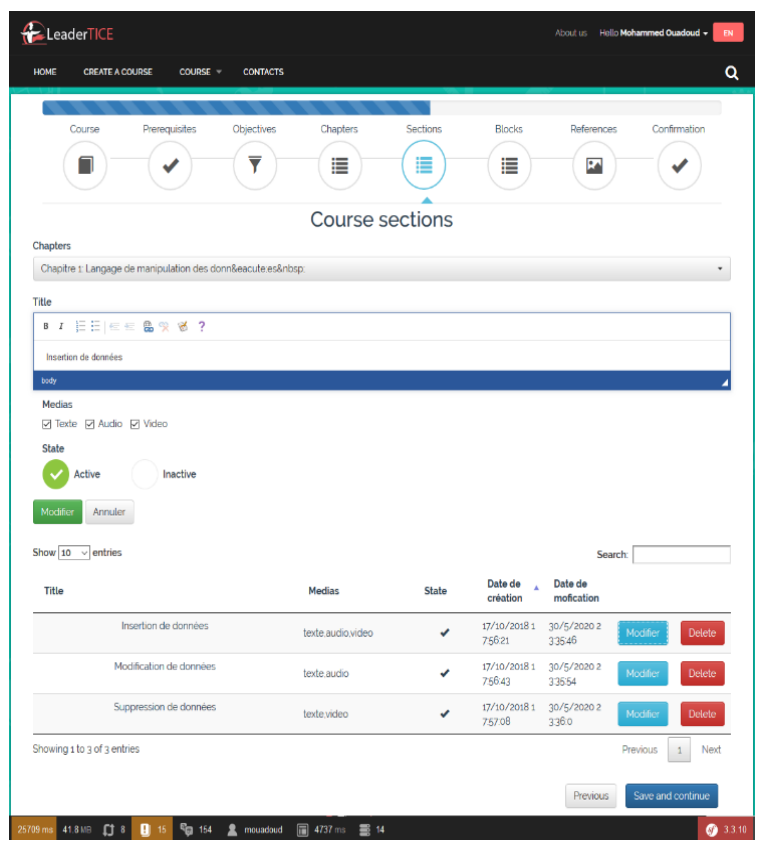

Fig. 7. Course sections interface developed by the NoSQL MongoDB database and the Symfony framework 
The block interface of a section: In the block interface of a chapter section (see Figure 8), the author/teacher has several privileges, which he needs to create the blocks of a section that meet academic standards. For this, we have given the author/professor the right to choose the chapter and section in which he wishes to add blocks. For each section block of a selected chapter, the author/teacher can insert the title and the content of the block.

To make the block active, by clicking on the "active" checkbox, if the block information is well written, or to leave it inactive, by clicking on the "inactive" checkbox, if the block information requires some modifications.

The course references interface: In the course references interface (see Figure $9-$ Appendix), the author/teacher has several privileges, which he needs for creating a course references that meet academic standards. For this, we have given the author/teacher the right to:

- Select the type of reference (article, chapter, book, thesis, manuscript, report, web page, etc.

- Add a title, publication date, and a summary of the reference

- Add the list of authors, to indicate the first, second ... until the last author for each reference

- Indicate the volume, issue, DOI, publication journal and numbers of the start and end page, to simplify the search for each reference.

Make the reference active, by clicking on the "active" checkbox, if the reference information is well written, or leave it inactive, by clicking on the "inactive" checkbox, if the reference information requires some modifications.

The general plan interface of a course: In the interface "general plan of a course" (see Figure 10 - Appendix), the learner has the right to see all the chapters, sub-chapters, and references of a course. He also has several means, which he needs to better understand a course that respects the learning style of each learner (visual, auditory, or audiovisual). For this, we gave the learner the right to choose the learning medium suited to his learning style, audio, video, image, text. 


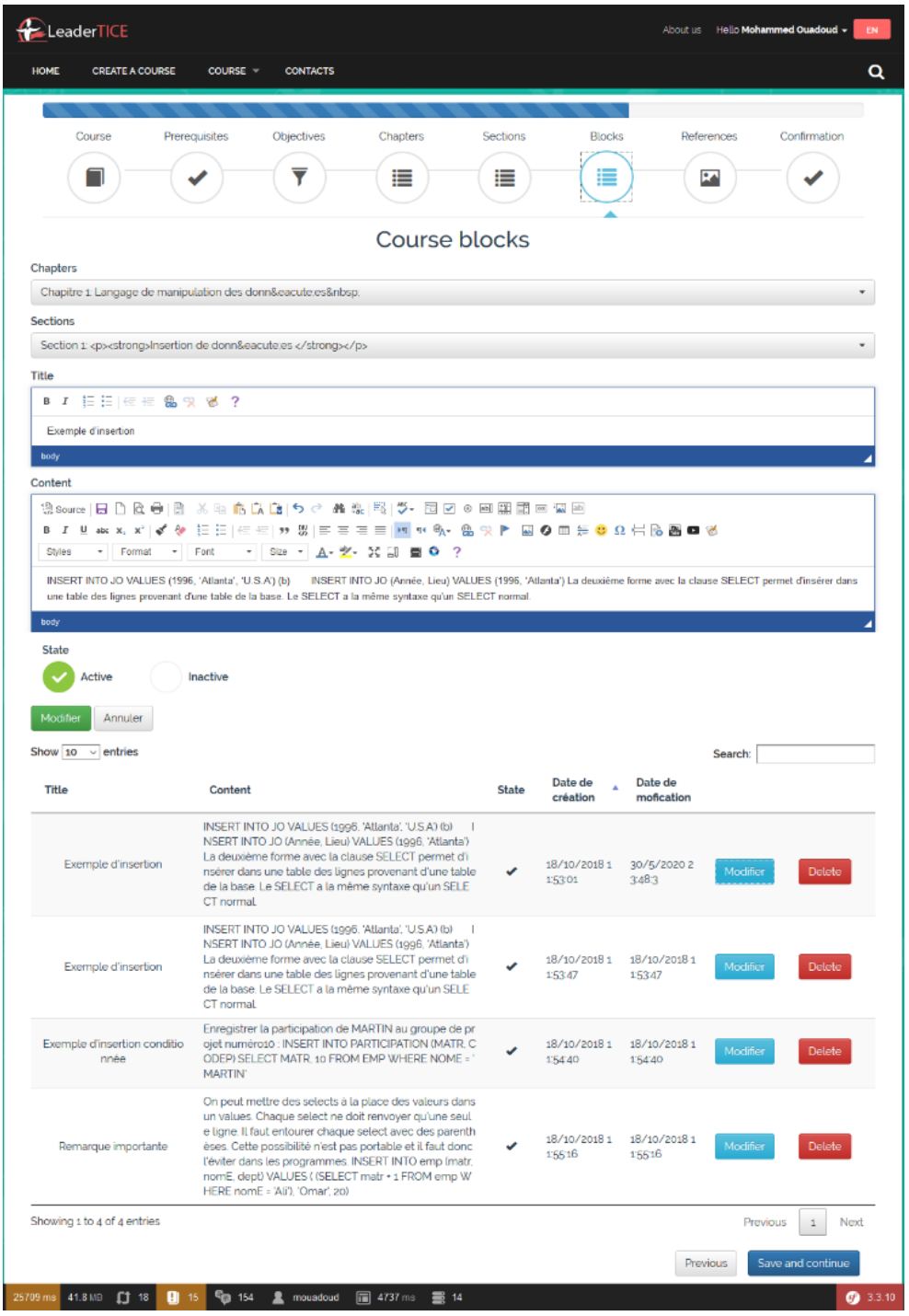

Fig. 8. Course blocs interface developed by the NoSQL MongoDB database and the Symfony framework

To make the section active, by clicking on the "active" checkbox, if the section information is well written or leave it inactive, by clicking on the "inactive" checkbox, if the section information requires some modifications.

The course details interface: In the "course details interface" (see Figure 11 - Appendix), the learner has several means, which he needs to better understand a course that respects each learner's learning style (visual, auditory, or audio-visual). The system after several choices of means of learning, few recommend the means of learning 
adapted to the learning style of each learner. At the end of each chapter, the learner must click on the following symbol to go to the next chapter.

\section{Conclusion and Perspectives}

We are on our way to the design and modeling of a new LMS compatible with IMSLD and NoSQL. This conception is based on active teachings centered on the learner, from which we opted for four learning theories as the teaching and learning base of this new LMS, namely traditional pedagogy, behaviorism, cognitivism, and social constructivism. This LMS allows us to achieve an educational object through the implementation of projects, activities and quizzes which are divided into tasks performed by the students, in collaboration or individually. To achieve our goal, we will develop the rest of our LMS via Symfony framework, which will facilitate the implementation phase.

\section{$8 \quad$ References}

[1] M. Ouadoud, M. Y. Chkouri, A. Nejjari, K. E. El-Kadiri, (2016) Studying and Analyzing the Evaluation Dimensions of ELearning Platforms Relying on a Software Engineering Approach. International Journal of Emerging Technologies in Learning (iJET). 2016, Vol. 11 Issue 1, p11-20. 10p. https://doi.org/10.3991/ijet.v11i01.4924

[2] M. Ouadoud, M. Y. Chkouri, A. Nejjari, and K. E. El-Kadiri, "Studying and comparing the free eLearning platforms," in 2016 4th IEEE International Colloquium on Information Science and Technology (CiSt), 2016, pp. 581-586. https://doi.org/10.1109/cist.2016. $\underline{7804953}$

[3] M. Ouadoud, M. Y. Chkouri, A. Nejjari, and K. E. El-Kadiri, "Exploring a Recommendation System of Free ELearning Platforms: Functional Architecture of the System," International Journal of Emerging Technologies in Learning (iJET), vol. 12, no 02, p. 219-226, Feb. 2017. https://doi.org/10.3991/ijet.v12i02.6381

[4] M. Ouadoud and M. Y. Chkouri, "Generate a Meta-Model Content for Sharing Space of Learning Management System Compatible with IMS-LD," in Innovations in Smart Cities Applications Edition 2, 2019, pp. 348-363. https://doi.org/10.1007/978-3-030-11196-0 31

[5] CEN/ISS WS/LT, Learning Technologies Workshop "Survey of Educational Modelling Languages (EMLs)".Version 1, September 2002.

[6] R. Koper, (2001). Modeling Units of Study from a Pedagogical Perspective, the pedagogical meta-model behind EML. http://eml.ou.nl/introduction/docs/pedmetamodel.pdf

[7] D. Burgos, M. Arnaud, P. Neuhauser, and R. Koper, "IMS Learning Design," Association EPI, Décembre-2005. [Online]. Available: http://www.epi.asso.fr/revue/articles/a0512c. htm. [Accessed: 03-Jan-2017].

[8] M. Ouadoud, M. Y. Chkouri, and A. Nejjari, "Learning Management System and the Underlying Learning Theories: Towards a new Modeling of an LMS," International Journal of Information Science and Technology (iJIST), vol. 2, no. 1, pp. 25-33, Mar. 2018.

[9] M. Ouadoud, A. Nejjari, M. Y. Chkouri, and K. E. El-Kadiri, "Learning Management System and the Underlying Learning Theories," in Innovations in Smart Cities and Applications, 2017, pp. 732-744. https://doi.org/10.1007/978-3-319-74500-8_67

[10] M. Ouadoud, N. Rida, and M. Y. Chkouri, "Designing an IMS-LD Model for Collaboration Space of Learning Management System," in 2018 IEEE 5th International Congress on 
Information Science and Technology (CiSt), 2018, pp. 380-385. https://doi.org/10. $\underline{1109 / \text { cist.2018.8596588 }}$

[11] M. Ouadoud and M. Y. Chkouri, "Designing an IMS-LD Model for Communication Space of Learning Management System," in Advanced Intelligent Systems for Sustainable Development (AI2SD'2018), 2019, pp. 40-54. https://doi.org/10.1007/978-3-030-11928-7_4

[12] M. Ouadoud, A. Nejjari, M. Y. Chkouri, and K. E. E. Kadiri, "Educational modeling of a learning management system," in 2017 International Conference on Electrical and Information Technologies (ICEIT), 2017, pp. 1-6. https://doi.org/10.1109/eitech.2017. $\underline{8255247}$

[13] M. Sadiq and M. Talbi, "Modélisation des unités d'apprentissage sur des plates-formes de formation à distance," Association EPI, Mar-2010. [Online]. Available: https://www.epi.asso.fr/revue/articles/a1003e.htm. [Accessed: 08-Sep-2016].

[14] E. Tonye, "Modeling a framework for open and distance learning in sub-Saharan African countries," frantice.net, numéro 2, December 2010.

[15] K. Chouchane, "Modélisation et réalisation d'une approche pour le m-learning," Magister en Informatique Option Système d'Informatique et de Communication (SIC) 2012, Université Hadj Lakhdar - Batna - Algérienne.

[16] S. Brunel, P. Girard, and M. Lamago, "Des plateformes pour enseigner à distance : vers une modélisation générale de leurs fonctions," in AIP Primeca 2015, La Plagne, France, 2015. [Online]. Available: https://hal.archives-ouvertes.fr/hal-01128532. [Accessed: 08-Sep2016].

[17] B. née Dahmani Farida, "Modélisation basée ontologies pour l'apprentissage interactif - Application à l'évaluation des connaissances de l'apprenant," $\mathrm{PhD}$ dissertation in computer science, Computer Science Department, Mouloud Mammeri University of Tizi-Ouzou, Algeria, 28 November, 2010. https://doi.org/10.15676/ijeei.2014.6.1.7

[18] Alfanet project "CopperCore V 3.3," Nov-2008. CopperCore is one of the OUNL's contributions to the Alfanet project [Online]. Available: http://coppercore.sourceforge.net. [Accessed: 04-Jan-2017].

[19] Bolton, "RELOAD Project: Editor," United Kingdom: The University of Bolton, The University of Strathclyde and JISC, 2005. [Online]. Available: http://www.reload.ac.uk/editor.html. [Accessed: 04-Jan-2017].

[20] F. El-Moudden, S. Aammou, and M. Khaldi. "A Tool to Generate a Collaborative Content Compatible with IMS-LD," International Journal of Software and Web Sciences, 11(1), December 2014-February 2015, pp. 01-08.

[21] M. Ouadoud, M. Y. Chkouri, and A. Nejjari, "LeaderTICE: A Platforms Recommendation System Based on a Comparative and Evaluative Study of Free ELearning Platforms," International Journal of Online Engineering (iJOE), vol. 14, no. 01, pp. 132-161, Jan. 2018. https://doi.org/10.3991/ijoe.v14i01.7865

[22] M. Ouadoud and M. Y. Chkouri, "Generate a Meta-Model Content for Disciplinary Information Space of Learning Management System Compatible with IMS-LD," in Proceedings of the 3rd International Conference on Smart City Applications, New York, NY, USA, 2018, p. 39:1-39:8. https://doi.org/10.1145/3286606.3286816

[23] F. El-Moudden, M. Khaldi, and S. Aammou, "Designing an IMS-LD Model for Collaborative Learning," IJACSA, vol. 1, no. 6, pp. 42-48.

[24] M. Ouadoud, T. Chafiq, and M. Y. Chkouri, "Designing an IMS-LD Model for Disciplinary Information Space of Learning Management System," in Proceedings of the 3rd International Conference on Smart City Applications, New York, NY, USA, 2018, p. 40:1-40:9. https://doi.org/10.1145/3286606.3286817 
[25] M. Ouadoud, T. Chafiq, N. Rida, and M. Y. Chkouri, "Generate a Meta-Model Content for Collaboration Space of Learning Management System Compatible with IMS-LD," International Journal of Interactive Mobile Technologies (iJIM), vol. 13, no. 1, pp. 37-52, Jan. 2019. https://doi.org/10.3991/ijim.v13i01.9440

[26] M. Ouadoud and M. Y. Chkouri, "Designing an IMS-LD Model for Sharing Space of Learning Management System," in Innovations in Smart Cities Applications Edition 2, 2019, pp. 334-347. https://doi.org/10.1007/978-3-030-11196-0_30

\section{Authors}

Mohammed Ouadoud is from Morocco. He is a Ph.D. in Computer sciences, at the Laboratory of the Information System and Software Engineering (SIGL) at National School of Applied Sciences, Abdelmalek Essaâdi University. In 2018, He completed his Ph.D. thesis in computer science at the faculty of science of Tetouan, Morocco. His dissertation research, focus on Modeling and Prototyping a Learning Management System Based on the IMD-LD, the NoSQL, and the Hybridization between Learning Theories. He has a Master degree in Multimedia Engineering of Instructional Design at the École Normale Supérieure of Martil, Morocco in 2013. His current research focuses on IT, E-learning, and Software Engineering. He is reviewer in several International journals. (E-mail: mohammed.ouadoud@gmail.com).

Tarik Marrakchi is a Data Engineer at Novelis France. He has more than 5 years of professional experience in Big Data and Information System projects in different sectors. In 2017, he got his engineering degree in information systems at SupMTI Oujda, Morocco. He has a Master's degree in Big Data \& Cloud Computing at the Faculty of Sciences Aïn-Chock of Casablanca, Morocco in 2018.

Rajae Taghzout received a degree in computer science from the National School of Applied Sciences Fez, in 2015, she joined Capgemini as a software engineer, and she has been a member of a technical team of BACTV, an e-learning platform for high school students, since 2017. She is currently development unity manager at University Hospital Center Oujda.

Article submitted 2020-10-06. Resubmitted 2020-11-18. Final acceptance 2020-11-18. Final version published as submitted by the authors. 


\section{Appendix}

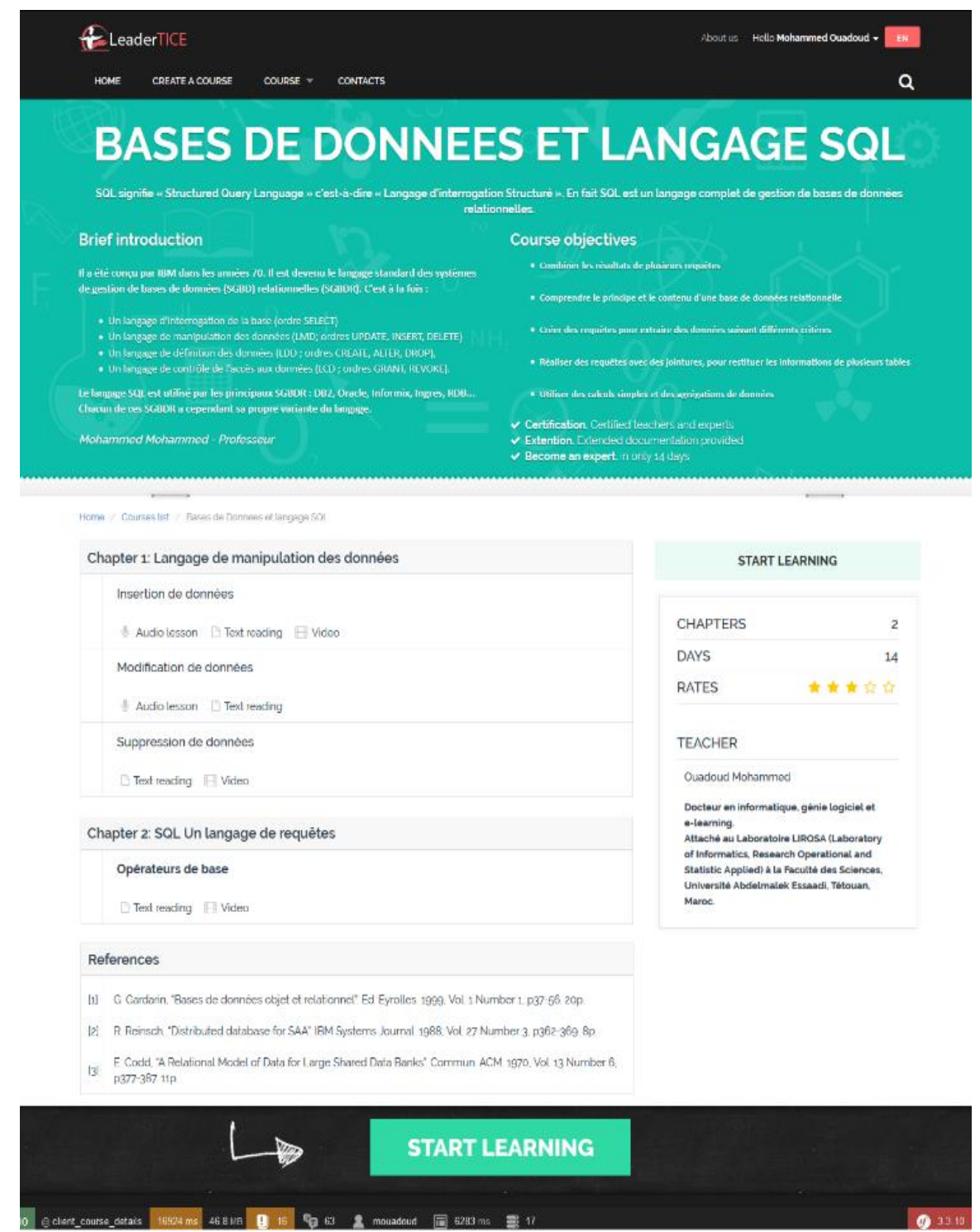

Fig. 9. General plan of a course developed via Sumfony Framework 


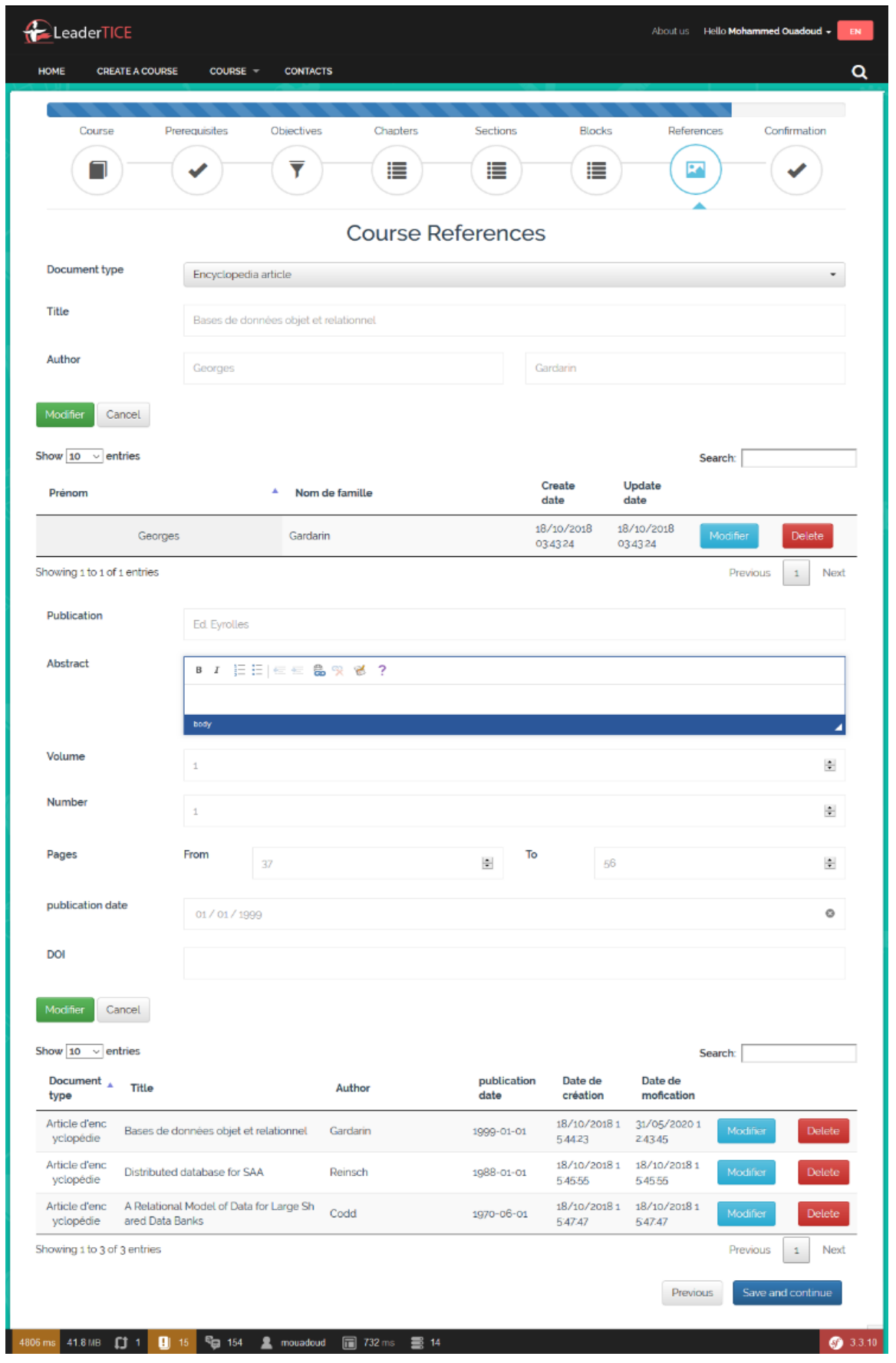

Fig. 10. Course references interface developed by the NoSQL MongoDB database and the Symfony framework 


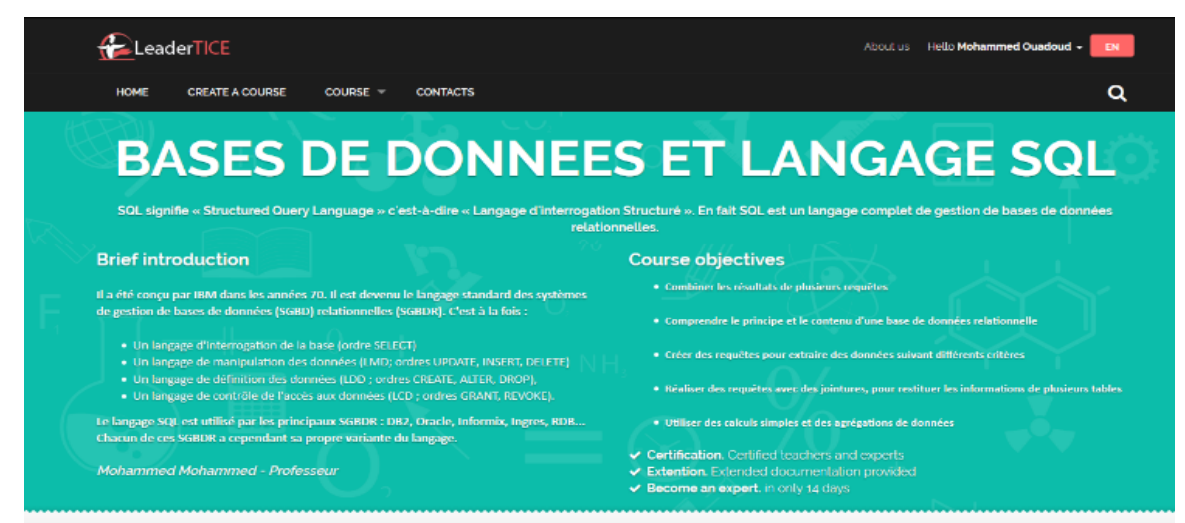

LANGAGE DE MANIPULATION DES DONNÉES
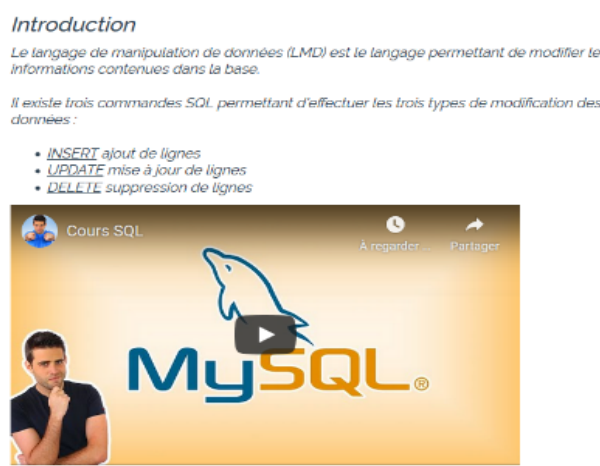

Insertion de données

Exemple dinsertion

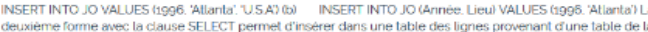

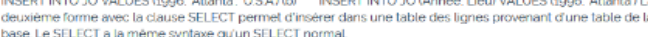

Exemple d'insertion

INSERT INTO JO

VALUES (19g6, 'Atlanta', "USA

(b) INSERT INTO JO

(Année. Lieu)

VALUES (19g6. 'Atlanta)

La deuxième forme avec la clause SELECT permet d'inserer dans une table des lignes provenant

Exemple d'insertion conditionnée

Entegistrer la participation de MARTIN au groupe de projel numéroto :

INSERT INTO PARTIIIPATION MMATR CODEPI

Conclusion

Les trols commandes (INSERT UPDATE et DEL ETE) travalltent sur la base telle quelle etait au debut

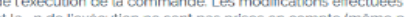

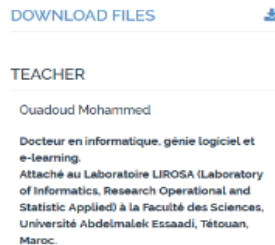

Maroce 